\title{
Las reformas de la regulación del trabajo doméstico por cuenta ajena en España
}

\author{
Elena DESDENTADO DAROCA \\ Universidad Nacional de Educación a Distancia \\ edesdentado@der.uned.es
}

Recibido: Octubre 2015

Aceptado: Noviembre 2015

\section{RESUMEN}

En este artículo se analizan las últimas reformas que se han producido en España en relación con el trabajo por cuenta ajena prestado en el hogar. El legislador español, influido por el Convenio $n^{\circ} 189$ de la OIT -que, sin embargo, no ha sido ratificado-, aborda en 2011 una profunda reforma del empleo doméstico. Esta reforma supuso un cambio importante, que ha afectado tanto a la regulación de las condiciones de trabajo de este colectivo como a su sistema de protección social. El objetivo de esta reforma ha sido aproximar la regulación del trabajo doméstico, en estos dos planos, a la regulación común de los trabajadores asalariados, aunque conservando ciertas particularidades. En el ámbito laboral, se mantiene la configuración del empleo doméstico como relación laboral especial, pero se reducen las diferencias con la relación laboral común. En el ámbito de la protección social, se procede a integrar el Régimen Especial de la Seguridad Social de los Empleados de Hogar en el Régimen General, aunque la integración es relativa pues se produce en el marco de un sistema especial. El artículo también examina las modificaciones normativas que, tras el cambio de Gobierno, tuvieron lugar en 2012.

Palabras clave: Empleado doméstico, empleador doméstico, hogar familiar, relación laboral especial, sistema especial de seguridad social.

\section{The Spanish reforms on domestic work regulation}

\begin{abstract}
This paper analyses the latest Spanish reforms regarding domestic work. The Spanish legislator, doubtlessly influenced by the ILO Domestic Work Convention $\mathrm{n}^{\circ} 189$ - which, however, was not later ratified in Spain- made a deep reform on domestic work in 2011. This legal reform implied a striking change that affected both working conditions and social security of employees in the family home. The aim of this reform has been to bring the regulation in domestic work closer to the general regulation for other workers, although maintaining certain specialties. Regarding working conditions, their setting as "particular employment relationship" has been held. However, the differences between this relationship and the common ones have been reduced. As for social security, domestic employees have been incorporated into the General Social Security System, but with important specialties, thus erasing the Special


Domestic Employees System. The paper also examines the legal changes that have taken place in this field after the new Government arose.

Keywords: Domestic employee, domestic employer, family home, special domestic service labor relationship, special social security scheme.

\section{EL PROCESO DE LABORALIZACIÓN DEL EMPLEO DOMÉSTICO Y SU CONFIGURACIÓN COMO “RELACIÓN LABORAL ESPECIAL"}

El trabajo doméstico, cuando se presta por cuenta ajena y en régimen de dependencia, cumple las notas típicas de la actividad laboral. Sin embargo, en España su encuadramiento en el Derecho del Trabajo es relativamente reciente y se articula, además, como relación laboral especial.

Hay razones objetivas que explican la resistencia histórica del ordenamiento laboral a entrar en el hogar. El Derecho del Trabajo surge como respuesta al conflicto obrero organizado, de forma colectiva, en torno a la fábrica. Pero en el empleo doméstico ni hay fábrica, ni hay un empresario en sentido tradicional y tampoco hay un conflicto que pueda manifestarse a través de las formas clásicas de lucha obrera. El trabajo doméstico está aislado en el hogar, no se organiza colectivamente, ni los trabajadores domésticos militan normalmente en las organizaciones sindicales, que no pueden desarrollar su acción en el marco del hogar familiar. Esto no significa que no haya conflicto de intereses entre empleador y empleado. Pero este conflicto no se regula a través de dos mecanismos esenciales en el ámbito laboral: la negociación colectiva y el conflicto colectivo. Por otra parte, la generalización del trabajo doméstico en las sociedades modernas provoca una especialidad añadida en este sector que aumenta la dificultad a la hora de abordar su regulación laboral y de Seguridad Social: la gran heterogeneidad del empleador del hogar, que, en la actualidad, puede tener capacidades económicas muy diferentes.

Debido a sus especialidades, el empleo doméstico quedó al margen del ordenamiento laboral durante muchos años. Como contrato de arrendamiento de servicios, se reguló por los arts. 1583 a 1587 del Código Civil.

El primer intento de laboralización del trabajo doméstico se produjo en la Ley de Contrato Trabajo de 1931, que calificaba el servicio doméstico prestado por cuenta y bajo dependencia ajenas como relación laboral (art. 2) y a "los ocupados en servicios domésticos" como trabajadores (art. 6). Se trató, sin embargo, de una laboralización muy relativa, pues el trabajo doméstico siguió excluido de la normativa específica prevista en materia de accidentes de trabajo, jornada, descansos y jurisdicción especial. En todo caso, el intento de laboralización se vio frustrado con la guerra civil y el advenimiento de la dictadura; la Ley de Contrato de Trabajo de 1944 vuelve a excluir el servicio doméstico del ordenamiento laboral, que seguirá rigiéndose por el Código Civil.

El siguiente intento se produce ya con la Ley 16/1976, de 8 de abril, de Relaciones Laborales, que acoge una solución intermedia: laboralizar el empleo doméstico -al que da el nombre de "servicio del hogar familiar"-, pero configurándolo 
como "relación laboral especial” [art. 3.1.a)], sometido a una normativa específica. Esta normativa específica debía abordarse por el Gobierno en el plazo de dos años; mientras tanto, el empleo doméstico seguiría rigiéndose por la normativa civil (disposición adicional $4^{\mathrm{a}}$ y disposición transitoria $1^{\mathrm{a}}$ ). La regulación reglamentaria nunca se produjo, por lo que la laboralización no llegó a materializarse.

Hay que esperar casi diez años más para la laboralización definitiva del trabajo doméstico. El Estatuto de los Trabajadores, aprobado en 1980, siguiendo el modelo de su antecesora configura el "servicio del hogar familiar" como "relación laboral de carácter especial” (art. 2.1.b) y fija un nuevo plazo, ahora de dieciocho meses, para que el Gobierno apruebe su regulación reglamentaria. La historia parecía que iba a repetirse, porque el plazo se volvió a superar, pero la Ley 32/1984 concedió otro plazo de doce meses que, finalmente, se cumplió con la aprobación del Real Decreto 1424/1985, de 1 de agosto.

El Real Decreto 1424/1985 constituyó la primera regulación laboral del servicio doméstico en España y, sin duda, supuso un avance respecto a la regulación civil anterior. Con él, finalmente, el empleo doméstico entra en el ámbito del Derecho del Trabajo y de la jurisdicción social, aunque sometido a normas especiales que afectan a importantes aspectos de la relación contractual. Estas normas especiales introducían un grado notable de flexibilidad en la regulación de las condiciones de trabajo. Se establecía, en primer lugar, una clara preferencia por la contratación temporal: el contrato se presumía concertado por tiempo determinado de un año y celebrado a prueba durante quince días (art. 4). Se flexibilizaba, además, la extinción del contrato de trabajo, permitiendo al empleador el "desistimiento" sin causa con una indemnización reducida (arts. 9 y 10). El tiempo de trabajo y el salario se sometían, también, a una regulación especial menos garantista (arts. 6 y 7).

\subsection{MARCO Y OBJETIVO DE LA REFORMA}

En los últimos años se constata una preocupación creciente por la precariedad en que se desarrolla el empleo doméstico. En el plano internacional destaca la labor de la OIT que, tras la elaboración de varios informes, adopta, en junio de 2011, el Convenio $n^{\circ} 189$ y la Recomendación $n^{\circ}$ 201, fijando una protección laboral mínima para los empleados domésticos.

El legislador español, influido por el Convenio $n^{0} 189$-que, sin embargo, no ratificará después-, aborda, en el mismo año 2011, la reforma laboral del empleo doméstico, junto con la reforma del sistema de protección social de este colectivo que después se examinará brevemente.

La reforma de la relación laboral especial del servicio del hogar familiar se encomienda al Gobierno en la disposición adicional 39a de la Ley 27/2011, de 1 de agosto; el mandato se cumple con la aprobación del Real Decreto 1620/2011, de 14 de noviembre, que sustituye a la normativa anterior. La nueva regulación entró en vigor el 1 de enero de 2012 y es aplicable a los contratos que estuvieran vigentes en esa fecha, aunque se exceptúa la nueva cuantía indemnizatoria prevista para el supuesto de 
extinción del contrato por desistimiento empresarial, que únicamente afecta a los contratos que se suscriban con posterioridad a la fecha de entrada en vigor.

El Real Decreto 1620/2011 parte de dos premisas: la necesidad de seguir configurando el empleo doméstico como relación laboral especial y la conveniencia de reducir las especialidades para equiparar en lo posible esta relación con la común. El preámbulo justifica la regulación especial por “el ámbito donde se presta la actividad, el hogar familiar, tan vinculado a la intimidad personal y familiar y por completo ajeno y extraño al común denominador de las relaciones laborales, que se desenvuelven en entornos de actividad productiva presididos por los principios de la economía de mercado". El hogar familiar explica, a su vez, "el vínculo personal basado en una especial relación de confianza que preside, desde su nacimiento, la relación laboral entre el titular del hogar familiar y los trabajadores del hogar”. Estas particularidades, según el preámbulo, “explican un tratamiento diferente respecto de la relación laboral común", pero la nueva normativa "pretende conjugar el mantenimiento de las diferencias, allí donde éstas encuentran una justificación objetiva y razonable, con la reducción o eliminación de aquellas, cuando se comprenda que su razón de ser ya no encuentra por más tiempo motivo, de manera que se logre una progresiva equiparación del bagaje jurídico de esta relación laboral especial con la común”.

\subsection{DELIMITACIÓN DE LA RELACIÓN LABORAL ESPECIAL DEL SERVICIO DEL HOGAR FAMILIAR Y SISTEMA DE FUENTES}

El art. 1.2 del RD 1620/2011 define la relación laboral especial del servicio del hogar familiar como "la que conciertan el titular del mismo, como empleador, y el empleado que, dependientemente y por cuenta de aquél, presta servicios retribuidos en el ámbito del hogar familiar”. Esta definición se completa en el número 4 de ese mismo precepto, que delimita el objeto de la relación, y en el art. 2, que establece una serie de exclusiones.

El objeto de la relación son los servicios prestados para el hogar familiar, entendiendo por tales "cualesquiera de las modalidades de las tareas domésticas", desde el cuidado de la casa hasta la atención de las personas que forman parte del hogar. El art. 1.4 incluye, expresamente, los servicios de guardería, jardinería y conducción de vehículos, cuando se prestan para el hogar.

Pero no todo trabajo doméstico en régimen de ajenidad y dependencia que se desarrolle en el hogar queda incluido en el ámbito de esta relación laboral especial. Se excluyen, en primer lugar, las relaciones concertadas por personas jurídicas (art. 2.1.a). La relación laboral especial del servicio del hogar familiar sólo se puede constituir entre particulares. Cuando el empleador es una persona jurídica, la relación laboral es común y, por tanto, se rige por la normativa laboral general. La norma insiste en esta idea cuando, en el art. 2.1.b) dispone que están asimismo excluidas las relaciones concertadas a través de empresas de trabajo temporal.

El trabajo doméstico realizado por familiares en principio también se excluye; no porque se vaya a regir por la regulación laboral común, sino porque, al presumirse no 
retribuido, queda al margen del Derecho del Trabajo. El art. 2.1.e) del Real Decreto 1620/2011 dispone, no obstante, que este tipo de trabajos se incluirá en el ámbito de la relación laboral especial cuando se acredite la condición de asalariado de quien presta los servicios. El precepto se remite a lo dispuesto en el art. 1.3.e) del Estatuto de los Trabajadores $^{1}$ (-en adelante, ET-), de acuerdo con el cual se consideran familiares, a estos efectos, siempre que convivan con el empleador, el cónyuge, los descendientes, ascendientes y demás parientes por consanguinidad o afinidad hasta el segundo grado inclusive y, en su caso, por adopción.

Debido a la ausencia de retribución, también quedan fuera de esta relación laboral especial los trabajos domésticos realizados a título de amistad, benevolencia o buena vecindad [art. 2.1.f)]. Y por la misma razón se excluyen "las relaciones de colaboración y convivencia familiar", entre las cuales la propia norma señala las relaciones "a la par", mediante las que se prestan, con carácter marginal, algunos servicios domésticos a cambio de comidas, alojamiento o simples compensaciones de gastos (art. 2.2).

Se contempla también expresamente la exclusión de los cuidados profesionales y no profesionales prestados a las personas dependientes conforme a lo dispuesto en la Ley 39/2006 de 14 de diciembre, de promoción de la autonomía personal y atención a las personas en situación de dependencia. Los cuidados profesionales se excluyen porque son contratados por instituciones públicas o por entidades privadas, es decir, por personas jurídicas; los no profesionales por su carácter familiar: estos trabajos se prestan por personas de la "familia o de su entorno" no vinculadas por un servicio de atención profesionalizada y la Ley 39/2006 prevé para ellos una prestación de carácter económico.

El art. 2 se cierra con una presunción problemática: cuando el empleado del hogar deba realizar, con cualquier periodicidad, otros servicios ajenos al hogar familiar en actividades o empresas de cualquier tipo del empleador, se presumirá la existencia de una única relación laboral común, salvo que se acredite el carácter esporádico o marginal de estos servicios no domésticos. Piénsese, por ejemplo, en la empleada del hogar que, además, limpia el bar del empleador. La solución es cuestionable, porque en principio lo lógico en estos casos sería reconocer la existencia de dos relaciones laborales diferentes: una especial -la limpieza y cuidado del hogar- y otra común -la limpieza del bar-. No obstante, debido a la dificultad que plantea acreditar el tiempo que la empleada dedica a una y otra actividad, la norma opta por presumir que la actividad predominante es la correspondiente a la relación laboral común, que absorbe a la especial. La norma no aclara qué pasa cuando se rompe la presunción y se acredita que los servicios ajenos al hogar son marginales. Podría entenderse que, en tal caso, opera también la absorción, pero en sentido contrario, considerando existente una única relación laboral de carácter especial. No parece, sin embargo, que esta interpretación pueda aceptarse; la finalidad tuitiva de la norma permite entender que en estos casos la absorción no entra en juego, de forma que existirían dos relaciones laborales diferentes: una relación laboral común marginal- y una relación laboral especial del servicio del hogar familiar.

${ }^{1}$ El texto refundido vigente del Estatuto de los Trabajadores fue aprobado por Real Decreto Legislativo 2/2015, de 23 de octubre. 
Esta relación laboral especial, así delimitada, se somete a un sistema de fuentes muy similar al previsto, con carácter general, en el art. 3 del ET, que recoge el mismo art. 3 del Real Decreto 1620/2011. Los derechos y obligaciones se regulan, en primer lugar, por las disposiciones de esta norma reglamentaria y, con carácter supletorio, en lo que resulte compatible con las especialidades de la relación, también por la normativa laboral común. Expresamente se exceptúa la aplicación del art. 33 del ET, relativo al Fondo de Garantía Salarial ${ }^{2}$.

Se menciona también como fuente de esta relación los convenios colectivos, aun cuando lo cierto es que, en la práctica, la negociación colectiva en este sector es inexistente. La razón se encuentra en las dificultades que plantea el control de la representatividad en este ámbito. La constitución de los sujetos de la negociación resulta, en efecto, muy complicada. Primero, porque no hay una organización empresarial que represente a los empleadores del hogar familiar y, de existir, sería, en la práctica, imposible medir su representatividad. Y segundo, porque, aun cuando los empleados del hogar pueden estar afiliados a las organizaciones sindicales más representativas o constituir sus propias asociaciones, su representatividad es muy difícil de establecer. Estos problemas explican la ausencia de convenios colectivos en este ámbito. Precisamente por ello, en algunas materias la regulación reglamentaria se extiende a aspectos que son propios de la negociación colectiva; el ejemplo paradigmático es la regulación del incremento salarial, que después comentaremos.

Junto a las normas legales y, en su caso, convencionales, el art. 3 menciona como fuente de la relación laboral la voluntad de las partes manifestada en el contrato de trabajo. Se trata de una fuente importante en esta relación, aun cuando la nueva normativa ha reducido su ámbito de forma significativa, al incluir un mayor número de normas de carácter imperativo que operan como límite a la autonomía de la voluntad.

Finalmente, son también fuente de esta relación los usos y las costumbres locales y profesionales.

\subsection{EL EMPLEADOR DOMÉSTICO: LAS INSUFICIENCIAS DE LA DEFINICIÓN LEGAL; EMPLEADOR FORMAL VS EMPLEADOR MATERIAL}

El art. 1.3 del Real Decreto 1620/2011 considera empleador “al titular del hogar familiar, ya lo sea efectivamente o como simple titular del domicilio o lugar de residencia en el que se presten los servicios domésticos”. La norma precisa que cuando esta prestación de servicios se realice para dos o más personas que, sin constituir una familia ni una persona jurídica, convivan en la misma vivienda, asumirá la condición de titular del hogar familiar quien asuma "la representación de tales personas, que podrá recaer de forma sucesiva en cada una de ellas” (art. 1.3).

\footnotetext{
${ }^{2}$ Esta exclusión, que se debe a la voluntad de no incrementar los costes de la contratación, resulta polémica pues el trabajador doméstico también está expuesto al riesgo de insolvencia del empleador.
} 
Esta definición del empleador doméstico, que se reitera en la normativa de Seguridad Social (art. 10.1.7 ${ }^{\circ}$ del RD 84/1996), resulta imprecisa y claramente insuficiente. La propia expresión "titular del hogar familiar" es inadecuada, pues no es posible ser "titular" de un "hogar", entendido este último, de acuerdo con el Diccionario de la Real Academia Española, como "familia o grupo de personas emparentadas que viven juntas". La familia no tiene un "titular", ni tampoco puede aceptarse que exista hoy un "cabeza de familia" o pater familias en el seno del hogar. Por otra parte, la norma afirma que se puede ser titular del hogar de forma efectiva o como simple titular del domicilio, pero ni se aclara cuándo se actúa "efectivamente" como titular del hogar, ni parece acertado equiparar la condición de empleador a quien simplemente ostenta la titularidad del domicilio donde se prestan los servicios domésticos. Tampoco resulta razonable atribuir la condición de empleador, en los supuestos de convivencia no familiar, a la persona que asuma la representación del grupo, y menos aún aceptar que esta condición pueda recaer "de forma sucesiva” en cada una de las personas que lo integran.

En realidad, la definición de empleador doméstico que da el art. 1.3 del RD 1620/2011 y que reitera, en materia de Seguridad Social, el art. 10.1.7 $7^{\mathrm{a}}$ del RD 84/1996, debe circunscribirse al empleador formal, es decir, al que asume, formalmente, las obligaciones que derivan de la normativa laboral y de Seguridad Social. Para identificar al empleador material del servicio doméstico hay que acudir, por el contrario, al concepto general de empresario laboral previsto en el art. 1.2 del ET: es empresario laboral o empleador quien dirige y retribuye la prestación de servicios, obteniendo los frutos del trabajo. La identificación del empleador real debe fundarse en estos elementos, que constituyen los criterios de calificación del trabajo incluido en el ámbito de aplicación de las normas laborales, contemplados desde la perspectiva de la posición empresarial en el contrato de trabajo.

Formalmente, un miembro de la familia o del grupo que convive puede asumir la condición de "titular del hogar" y, como tal, suscribir el contrato de trabajo, haciéndose responsable de las obligaciones en materia laboral y de Seguridad Social; pero es importante insistir en que para determinar quién es realmente empleador en esa familia o en ese grupo habrá que determinar para quién se presta el servicio doméstico, quién lo retribuye y quién lo dirige y organiza. Si, además de quien formalmente aparece como "titular del hogar", otros miembros de la familia o del grupo actúan como empresarios de acuerdo con lo dispuesto en el art. 1.2 del ET, habrá que entender que existe una posición empresarial plural, que se traduce en una responsabilidad solidaria de todos ellos con respecto a las obligaciones laborales y de Seguridad Social.

\subsection{LA CONTRATACIÓN: ACCESO AL EMPLEO, FORMA DEL CONTRATO Y MODALIDADES DE CONTRATACIÓN}

La contratación de los empleados del hogar se puede realizar directamente o por intermediación de los servicios públicos de empleo o de las agencias de colocación debidamente autorizadas.

El contrato de trabajo puede concertarse por escrito o verbalmente, aunque se impone la forma escrita cuando lo requiera, por disposición legal, una modalidad 
contractual determinada y, en todo caso, cuando el contrato sea de duración determinada por período igual o superior a cuatro semanas. Además, cualquiera de las partes puede exigir a la otra que el contrato se formalice por escrito, no sólo en el momento de constituirse la relación sino durante el transcurso de la misma.

Cuando la duración de la relación laboral sea superior a cuatro semanas, se establecen dos reglas especiales. En primer lugar, en defecto de pacto escrito el contrato se presumirá concertado por tiempo indefinido y a jornada completa, salvo prueba en contrario que acredite su naturaleza temporal o el carácter parcial de los servicios (art. 5.2). En segundo lugar, el trabajador deberá recibir del empleador información sobre los elementos esenciales del contrato y las principales condiciones de ejecución de la prestación laboral (art. 5.4) ${ }^{3}$, medida con la que se pretende lograr una mayor transparencia en la relación laboral, dejando claros los derechos y obligaciones de cada una de las partes.

El contrato con el empleado doméstico puede celebrarse por tiempo indefinido o por una duración determinada. Ahora bien, el contrato por duración determinada sólo será posible en los términos previstos en el art. 15 del ET. La preferencia del legislador es a favor del contrato indefinido, que, como se ha dicho, se presume a falta de pacto escrito en los contratos de duración superior a los cuatro meses. El cambio con respecto a la normativa anterior es notable; bajo el Real Decreto 1424/1985, las partes podían optar por el contrato indefinido o por el contrato temporal y, en defecto de pacto escrito, el contrato se presumía concertado por tiempo determinado de un año, prorrogable tácitamente por períodos igualmente anuales sin límite de tiempo. Este “contrato anual no causal” desaparece con la reforma de 2011.

También hay cambios importantes en el período de prueba. En el régimen anterior la relación se presumía celebrada a prueba durante quince días; bajo el nuevo régimen, el período de prueba no se presume y se rige por la normativa laboral común recogida en el art. 14 del ET, en virtud del cual dicho período de prueba debe concertarse por escrito, por el tiempo que establezcan los convenios colectivos. A falta de convenio que en esta relación laboral especial será lo habitual-, el art. 7 del Real Decreto 1620/2011 dispone que el período de prueba no deberá exceder de dos meses. Las partes podrán pactar que la resolución de la relación laboral por cualquiera de ellas durante este período exija un preaviso no superior a siete días naturales.

\subsection{EL CONTENIDO DE LA RELACIÓN LABORAL ESPECIAL DEL SERVICIO DEL HOGAR FAMILIAR: DERECHOS Y DEBERES, RETRIBUCIÓN Y TIEMPO DE TRABAJO}

El art. 7 del Real Decreto 1620/2011 establece, con carácter general, que el empleado doméstico tendrá los derechos y deberes laborales previstos en la regulación

\footnotetext{
${ }^{3}$ El art. 5.4 del Real Decreto se remite, en este punto, al Real Decreto 1659/1998, de 24 de julio, por el que se desarrolla el art. 8.5 del Estatuto de los Trabajadores en materia de información al trabajador sobre los elementos esenciales del contrato de trabajo.
} 
laboral común (arts. 4 y 5 del ET), aunque lo cierto es que algunos de estos derechos y deberes son de difícil aplicación al ámbito doméstico, como el derecho de reunión o el deber de no concurrir en la actividad de la empresa.

En materia de prevención de riesgos, hay que tener en cuenta que la Ley 31/1995, de 8 de noviembre, de Prevención de Riesgos, en su art. 3.4 excluye de su ámbito de aplicación la relación laboral de carácter especial del servicio del hogar familiar ${ }^{4}$, si bien impone para el trabajo doméstico una regla general de cuidado en virtud de la cual "el titular del hogar familiar está obligado a cuidar de que el trabajo de sus empleados se realice en las debidas condiciones de seguridad e higiene”. Esta regla se reproduce en el art. 7.2 del Real Decreto 1620/2011, que menciona expresamente la obligación del empleador de "adoptar medidas eficaces" con esta finalidad, "teniendo debidamente en cuenta las características específicas del trabajo doméstico”. El precepto añade que "el incumplimiento grave de estas obligaciones será justa causa de dimisión del empleado", lo que resulta criticable, pues en estos casos lo razonable es que el trabajador pueda solicitar la resolución del contrato de trabajo con la indemnización correspondiente al despido improcedente. En todo caso, en materia de prevención de riesgos el problema fundamental es la dificultad que plantea el control de la obligación de cuidado impuesta al empleador, dado que la inviolabilidad del domicilio limita en gran medida la actuación inspectora ${ }^{5}$. Es un problema que afecta, en general, a todo el régimen de garantías aplicable a esta relación laboral especial.

El régimen salarial se aborda en el art. 8 del Real Decreto 1620/2011. Comienza el precepto disponiendo, como ya lo hiciera la normativa anterior, que el salario mínimo interprofesional fijado anualmente por el Gobierno es exigible a esta relación laboral especial. La norma precisa que el salario mínimo se entiende referido a la jornada de trabajo completa, percibiéndose a prorrata si se realizase una jornada inferior. Más adelante, en el apartado 5 del art. 8, se establece una regla especial para los empleados de hogar "que trabajen por horas, en régimen externo", para quienes el salario mínimo de referencia será el que se fije por el Gobierno para los trabajadores eventuales y temporeros, que incluye todos los conceptos retributivos (parte proporcional de domingos y festivos, pagas extraordinarias y vacaciones); este salario debe abonarse "íntegramente en metálico, en proporción a las horas efectivamente trabajadas" . La referencia a los empleados de hogar "que trabajen por horas" resulta

${ }^{4}$ La exclusión parece justificada, pues no es posible exigir al empleador doméstico las obligaciones que, con carácter general, impone la Ley de Prevención de Riesgos a los empresarios. Esto no significa que el trabajo doméstico carezca de riesgos profesionales; de hecho, como después veremos, la protección social de los empleados del hogar incluye las contingencias profesionales.

${ }^{5}$ La Inspección de Trabajo y de la Seguridad Social necesitará la autorización del titular del domicilio para poder entrar en el hogar donde se desarrolla la prestación; en su defecto, deberá solicitar la autorización judicial, con la consiguiente demora en la actividad inspectora y el riesgo de ocultación de los actos constitutivos de infracción.

${ }^{6}$ El salario mínimo para 2016 se fija en 21,84 euros/día y 655,20 euros/mes. Para los empleados de hogar "por horas, en régimen externo", el salario mínimo, que incluye todos los conceptos 
imprecisa, aunque, por remisión a la regulación específica del salario mínimo interprofesional de los trabajadores eventuales y temporeros, hay que entender que el empleado doméstico "por horas" es aquel cuyos servicios a un empleador no exceden de ciento veinte días al año?

La primera novedad importante en materia retributiva afecta al salario en especie, cuya regulación se equipara ahora a la normativa laboral común: el salario en especie no puede superar el 30\% del salario total y, además, en todo caso, se debe garantizar el pago en metálico, al menos, de la cuantía del salario mínimo interprofesional en cómputo mensual ${ }^{8}$.

Para los incrementos salariales, la norma se remite, en primer lugar, a la autonomía privada. Los incrementos salariales, dice el apartado 2 del art. 8, "deberán determinarse por acuerdo entre las partes”. En defecto de acuerdo, se aplicará "un incremento salarial anual igual al incremento salarial medio pactado en los convenios colectivos según la publicación del Ministerio de Trabajo e Inmigración del mes en que se completen doce consecutivos de prestación de servicios"”. Se trata de una norma polémica. En primer lugar, se impone, en todo caso, un incremento salarial anual: o se acuerda por las partes tal incremento o se aplica el incremento salarial medio de la negociación colectiva, pero, dado el tenor literal de la norma, no parece posible que el empleador y el empleado del hogar puedan acordar que, respetando el salario mínimo interprofesional, no se produzca incremento salarial anual. En este sentido, la regulación es mucho más rígida que la establecida, con carácter general, para regular los salarios en la negociación colectiva. Por otra parte, la remisión al incremento salarial medio pactado en los convenios, aparte de resultar excesivamente compleja, implica que un sector sin negociación colectiva va a experimentar unos incrementos del salario superiores a todos los sectores con negociación que queden por debajo de la media, una circunstancia difícil de justificar, teniendo en cuenta, además, las características del empleador medio en el ámbito doméstico.

En relación con las pagas extraordinarias, el art. 8.4 dispone que el empleado tiene derecho a dos gratificaciones extraordinarias al año cuya cuantía "será la que acuerden las partes, debiendo ser suficiente para garantizar, en todo caso, el pago en metálico, al menos, de la cuantía del salario mínimo interprofesional en cómputo anual”. Lo que la norma pretende garantizar es que con las pagas extraordinarias se cubra el salario mínimo interprofesional en cómputo de catorce meses, es decir,

retributivos, es de 5,13 euros por hora efectivamente trabajada (arts. 1 y 4.2 del Real Decreto $1171 / 2015$, de 29 de diciembre).

${ }^{7}$ Vid. art. 4.1 del Real Decreto 1171/2015, de 29 de diciembre.

${ }^{8}$ Bajo la normativa anterior, las prestaciones en especie podían alcanzar el $45 \%$ del salario total y no se garantizaba la retribución en metálico del salario mínimo interprofesional (art. 6.2 del Real Decreto 1424/1985).

${ }^{9}$ La regulación anterior reconocía al empleado del hogar el derecho a un incremento del salario en metálico de un 3\% del mismo por cada tres años naturales de vinculación con un empleador, con un máximo de cinco trienios (art. 6.3 del Real Decreto 1424/1985). 
incluidos los meses correspondientes a las pagas extraordinarias ${ }^{10}$. El problema se plantea cuando se pacta un salario mensual superior al salario mínimo interprofesional en cómputo de catorce pagas, pero no se acuerda nada respecto a las pagas extraordinarias, que no se abonan. Piénsese, por ejemplo, que el empleado cobra al mes 1000 euros de salario, lo que, en doce meses, supone 12.000 euros, una cuantía superior al salario mínimo interprofesional en cómputo anual, que, para 2016, es de 9.172,80 euros. En principio, podría admitirse que, en el supuesto planteado, existe un prorrateo implícito de las pagas extraordinarias en doce meses. Ahora bien, el art. 8.4 del Real Decreto no prevé la posibilidad de prorratear estas pagas y la regulación laboral común sólo admite el prorrateo cuando se acuerde en convenio colectivo (art. 31.2 ET), posibilidad que en el sector doméstico queda cerrada por la ausencia de negociación colectiva. Ante esta situación, se podría entender que el empleado del hogar puede reclamar del empleador el pago de dos gratificaciones extraordinarias cuya cuantía, a falta de previsión expresa, sería equivalente al salario mensual. Sin embargo, hay que tener en cuenta que la finalidad del art. 8.4 del Real Decreto 1620/2011 es, en definitiva, garantizar que, con las pagas extraordinarias, se cubra el salario mínimo interprofesional en cómputo anual, lo que, en el caso, se cumple. Parece, por tanto, más razonable mantener que, en efecto, existe un acuerdo implícito de prorratear las pagas extraordinarias, aunque tal prorrateo implique un incumplimiento de la normativa laboral susceptible de ser sancionado.

Otra novedad importante en relación con el salario es la obligación de documentar su pago. El empleador debe entregar al trabajador un recibo individual y justificativo del pago del salario. Para facilitar la labor al empleador, se dispone que el Ministerio competente deberá poner a su disposición modelos de recibos de salarios. Se trata de una medida más para fortalecer la transparencia de esta relación laboral especial y, sin duda, aporta seguridad tanto al empleado como al empleador, aunque su nivel de observancia dependerá de la mayor o menor complejidad de esos modelos oficiales de recibos de salarios.

El tiempo de trabajo también experimenta con la reforma de 2011 cambios significativos (art. 9). En primer lugar, el horario ya no se fija de forma unilateral por el empleador, como establecía el Real Decreto 1424/1985, sino por acuerdo entre las partes. Por su parte, la jornada máxima semanal de carácter ordinario se mantiene en cuarenta horas, sin incluir los tiempos de presencia en los que el empleado está a disposición del empleador sin prestar trabajo efectivo. El descanso entre jornadas se incrementa, de modo que entre el final de una jornada y el inicio de la siguiente debe mediar un descanso mínimo de doce horas, al igual que en la relación laboral común; no obstante, se prevé una norma especial para el empleado interno cuyo descanso entre jornadas puede reducirse a diez horas, compensando el resto hasta doce horas en

\footnotetext{
${ }^{10}$ El Real Decreto 1171/2015, de 29 de diciembre, en su art. 3.1 dispone que el salario mínimo interprofesional en cómputo anual no podrá ser inferior a 9.172,80 euros, cantidad que corresponde al salario mínimo interprofesional mensual (655,20 euros/mes) de catorce meses.
} 
períodos de hasta cuatro semanas ${ }^{11}$. La norma reglamentaria no fija un máximo de horas de trabajo efectivo diario, por lo que resulta aplicable lo dispuesto en el art. 34.3 del ET, que fija el tope en nueve horas diarias de trabajo efectivo, aunque admite otra distribución del tiempo de trabajo diario siempre que se respete el descanso entre jornadas.

El empleador y el empleado pueden pactar "tiempos de presencia”, respetando los períodos mínimos de descanso establecidos. El Real Decreto 1620/2011 no define estos tiempos de presencia, como tampoco lo hacía su antecesor; se trata, como ya señalamos, de períodos de tiempo en los que el empleado está a disposición del empleador pero sin realizar un trabajo efectivo, de ahí que no computen a efectos de determinar la jornada máxima laboral. Por lo tanto, no es tiempo efectivo, ni tampoco tiempo de descanso, sino tiempo de disposición; si, durante el tiempo de presencia el empleador necesitara los servicios del empleado, el tiempo pasaría a ser de trabajo efectivo. En teoría parece claro, aunque lo cierto es que en la práctica no es fácil delimitar estos períodos de tiempo ${ }^{12}$. La nueva regulación aclara, en todo caso, que los tiempos de presencia tendrán la duración que acuerden las partes y deberán ser retribuidos o compensados, precisando que, salvo que se acuerde su compensación con períodos equivalentes de descanso retribuido, las horas de presencia no podrán exceder de veinte horas semanales de promedio en un período de referencia de un mes y se retribuirán con un salario de cuantía no inferior al correspondiente a las horas ordinarias.

En cuanto al régimen de las horas extraordinarias, el art. 9.3 del Real Decreto se remite a la regulación laboral común prevista en el art. 35 del ET, aunque se excluye la aplicación del apartado 5 de este precepto, que impone al empresario la obligación de registrar, día a día, la jornada de cada trabajador con el fin de totalizar las horas ordinarias y extraordinarias de trabajo en el período fijado para el abono de las retribuciones, entregando copia del resumen al trabajador en el recibo correspondiente. Esta obligación no afecta, por tanto, al empleador doméstico. La exclusión, que sin duda pretende evitar un exceso de cargas de gestión al empleador del hogar, ha sido, sin embargo, criticada por la doctrina científica, que, con acierto, advierte de la especial dificultad que implica probar en el trabajo doméstico la realización de las horas extraordinarias (Ruano 2013: p. 104; Miñarro 2013: p 50). Hay que tener en cuenta que, de acuerdo con el art. 217.2 de la Ley de Enjuiciamiento Civil (LEC), corresponde al empleado del hogar probar la efectiva prestación de las horas extraordinarias de trabajo y, dado que éstas se realizan en el ámbito del hogar, la prueba se limitará muy frecuentemente al interrogatorio de las partes, que se valorará por el juez según las reglas de la sana crítica (art. 316.2 LEC).

Una vez concluida la jornada diaria de trabajo y, en su caso, el tiempo de presencia pactado, la norma dispone que "el empleado no estará obligado a permanecer

${ }^{11}$ El Real Decreto 1424/1985 fijaba entre una y otra jornada un descanso mínimo de diez horas cuando el empleado de hogar no pernocta en el domicilio, y de ocho horas, en caso contrario (art. 7.1).

12 Vid. SSTSJ País Vasco, 24.4.2001 (JUR 2001/301697) y Andalucía, Sevilla, 31.5.2012 (AS 2012/2324). 
en el hogar familiar”, una aclaración que está especialmente dirigida al empleado interno.

Respecto al descanso dentro de la jornada de trabajo, el art. 8.4 establece que el empleado interno dispondrá, al menos, de dos horas diarias para las comidas principales, tiempo que no computa como trabajo efectivo. La norma, que se limita a reproducir lo que ya establecía el Real Decreto 1424/1985, no hace ninguna referencia a los empleados de hogar externos, que se rigen en esta materia por la regulación laboral común, en virtud de la cual siempre que la duración de la jornada diaria continuada exceda de seis horas, deberá establecerse un período de descanso durante la misma de duración no inferior a quince minutos, período que únicamente se considerará tiempo de trabajo efectivo cuando así esté establecido o se establezca por convenio colectivo o contrato de trabajo (art. 34.4 ET).

El descanso semanal se fija en treinta y seis horas consecutivas ${ }^{13} \mathrm{y}$, como regla general, debe abarcar la tarde del sábado o la mañana del lunes y el día completo del domingo. Cuando el empleado del hogar no preste servicios en régimen de jornada completa, la retribución correspondiente al período de descanso se reducirá en proporción a las horas efectivamente trabajadas.

Para el derecho al disfrute de las fiestas y permisos, el Real Decreto 1620/2011 se remite a la normativa laboral común, prevista en el art. 37 del ET. El período de vacaciones anuales, por su parte, se mantiene en treinta días naturales y puede fraccionarse en dos o más períodos, si bien al menos uno de ellos debe ser, como mínimo, de quince días naturales consecutivos. El período de disfrute de las vacaciones se ha de fijar por acuerdo entre las partes, pero ahora la nueva regulación añade que, a falta de acuerdo, quince días podrán fijarse por el empleador y el resto se elegirá libremente por el empleado; en este último caso, se exige que las fechas de las vacaciones sean conocidas con dos meses de antelación al inicio de su disfrute. Se aclara, además, que durante las vacaciones el empleado no está obligado a residir en el domicilio familiar o en el lugar a donde se desplace la familia o alguno de sus miembros.

Finalmente, respecto al tiempo de trabajo de los empleados de hogar menores de dieciocho años, el art. 9.8 del Real Decreto 1620/2011 impone los mismos límites ya establecidos, con carácter general, en el Estatuto de los Trabajadores.

${ }^{13}$ El Real Decreto 1424/1985 también fijaba el descanso semanal en treinta y seis horas, pero tan sólo imponía el carácter consecutivo de veinticuatro horas. El disfrute del resto de horas de descanso se remitía al acuerdo entre las partes (art. 7.3). 


\subsection{GARANTÍAS EN LOS SUPUESTOS DE CAMBIO DE EMPLEADOR, CAMBIO DE LOCALIZACIÓN DEL HOGAR Y SUSPENSIÓN DEL CONTRATO DE TRABAJO POR INCAPACIDAD TEMPORAL}

El art. 10 del Real Decreto 1620/2011 establece una regulación especial para los supuestos de cambio de empleador, cambio de localización del hogar y suspensión del contrato de trabajo por incapacidad temporal del empleado doméstico.

Cuando se produzca un cambio en la persona del empleador, la subrogación contractual (art. 44 del ET) sólo procederá previo acuerdo de las partes. Este acuerdo, no obstante, se presume cuando el empleado siga prestando servicios en el mismo domicilio durante al menos siete días, pese a haber variado la titularidad del hogar familiar.

Si el hogar familiar se traslada a una localidad distinta y el traslado es temporal, el empleador y el empleado podrán acordar la suspensión del contrato de trabajo. Si, por el contrario, el traslado es definitivo, cualquiera de las partes podrá optar por desistir de la relación laboral. Cuando es el empleador el que opta por la extinción, deberá comunicar su decisión al empleado por escrito y se aplicará el régimen previsto para el desistimiento empresarial, que se examinará en el próximo epígrafe. Cuando es el empleado el que desea extinguir la relación, deberá también comunicarlo al empleador -aunque no se exige en este caso la comunicación escrita- y tendrá derecho a percibir la indemnización que corresponde al desistimiento empresarial.

Finalmente, el art. 10 dispone que, en los supuestos de suspensión del contrato de trabajo por incapacidad temporal del empleado del hogar, si éste es interno tendrá derecho a permanecer alojado en el domicilio un mínimo de treinta días, salvo que, por prescripción médica, se recomiende su hospitalización. Se trata de una norma oportuna, pues, al tener el empleado interno su residencia en el domicilio del empleador, puede que no disponga, en principio, de ningún otro lugar en el que alojarse. La norma garantiza que, al menos durante los primeros treinta días de la baja por incapacidad temporal, el empleado podrá continuar residiendo en el hogar familiar. Esta garantía debe operar aun cuando, durante esos primeros treinta días, el empleador opte por el desistimiento de la relación laboral.

\subsection{EL RÉGIMEN DE EXTINCIÓN DEL CONTRATO DE TRABAJO}

El Real Decreto 1620/2011 regula en su art. 11 la extinción del contrato de trabajo, introduciendo importantes modificaciones que pretenden reforzar las garantías de los empleados.

Las causas extintivas son las previstas en el art. 49.1 del ET, con tres exclusiones: 1) la extinción por fuerza mayor constatada por la autoridad laboral; 2) la extinción por despido colectivo fundado en causas económicas, técnicas, organizativas o de producción y 3) la extinción por causas objetivas legalmente procedentes. Además, se 
añade una causa extintiva específica de esta relación laboral especial, que ya existía en la normativa anterior: el desistimiento del empleador.

La regulación especial prevista en art. 11 del Real Decreto afecta al despido disciplinario y al desistimiento del empleador.

El despido disciplinario debe estar fundado en alguna de las causas previstas en el art. 54 del ET y ha de comunicarse por escrito al empleado; aunque la norma no lo especifique, en esta comunicación escrita el empleador debe hacer constar los hechos que motivan el despido y la fecha en que tendrá efectos (art. 55.1 ET). Para el supuesto en el que el despido sea declarado improcedente, se establece una indemnización de veinte días de salario por año de servicio, con un tope de seis mensualidades, inferior, por tanto, a la prevista, con carácter general, en el art. 56 del ET. La norma no alude a la readmisión, pero, de acuerdo con el art. 56 del ET, hay que entender que en los supuestos en que el despido se declare improcedente, el empleador podrá optar entre la readmisión del empleado (asumiendo el pago de los salarios de tramitación -art. 56.2 ET-) o la indemnización especial prevista en el art. 11 del RD 1620/2011

El art. 11 del Real Decreto tampoco alude al despido nulo por vulneración de derechos fundamentales o por cualquier otra de las causas previstas en el art. 55.5 del ET. Ante el silencio de la norma caben varias interpretaciones. Podría entenderse que en esta relación laboral especial no existe la figura del despido nulo, por lo que en los supuestos previstos en el art. 55.5 del ET el despido debería calificarse de improcedente e indemnizarse conforme a la norma especial. Esta tesis no resulta satisfactoria, pues los supuestos de nulidad merecen un especial reproche por parte del ordenamiento jurídico ${ }^{15}$. Actualmente, la mayoría de la doctrina acepta la nulidad del despido en el servicio doméstico, aunque matizan sus consecuencias, pues la necesidad de garantizar el derecho fundamental a la intimidad familiar del empleador impide que pueda imponerse en el ámbito del hogar la readmisión obligatoria del empleado ${ }^{16}$. Frente a este escollo, se ofrecen dos soluciones. La primera consiste en imponer una

14 Quizás lo más razonable en estos casos sería aplicar la misma solución prevista para la relación laboral especial de alta dirección, en virtud de la cual procede la indemnización salvo que las partes, de común acuerdo, opten por la readmisión (art. 11.3 del Real Decreto 1382/1985, de 1 de agosto).

${ }^{15}$ Hay que tener en cuenta, además, que, de acuerdo con el art. 10 de la Ley Orgánica 3/2007, de 22 de marzo, para la igualdad efectiva de mujeres y hombres, "los actos y las cláusula de los negocios jurídicos que constituyan o causen discriminación por razón de sexo se considerarán nulos y sin efecto, y darán lugar a responsabilidad a través de un sistema de reparaciones o indemnizaciones que sean reales, efectivas y proporcionadas al perjuicio sufrido, así como, en su caso, a través de un sistema eficaz y disuasorio de sanciones que prevenga la realización de conductas discriminatorias”.

${ }^{16}$ No obstante, la Sentencia del Juzgado de lo Social $n^{\circ} 31$ de Madrid de 16 de abril de 2008 (sentencia $n^{\circ}$ 178/2008) declaró nulo el despido de una empleada de hogar embarazada imponiendo su readmisión obligatoria. Se trata, sin embargo, de un pronunciamiento aislado. La doctrina judicial mayoritaria entiende que en el ámbito del hogar familiar no es posible imponer la readmisión. 
indemnización, pero de cuantía equivalente a la prevista en la regulación laboral común para el despido improcedente; de esta forma, la sanción del despido nulo sería superior a la del despido improcedente, que, para esta relación laboral especial, como vimos, tiene una indemnización inferior. La mayoría de la doctrina científica y judicial se muestra partidaria de esta solución, aunque puede resultar algo forzada, dada la ausencia de previsión normativa en este sentido ${ }^{17}$. Otra opción, más acorde con la regulación laboral común, sería aplicar el art. 286 de la Ley 36/2011, de 10 de octubre, reguladora de la jurisdicción social (LRJS), precepto previsto para los supuestos en los que no es posible la readmisión del trabajador, tal y como sucede en el ámbito doméstico; esta solución implica una condena a la readmisión en la sentencia que luego se transformaría en el pago de la indemnización correspondiente al despido improcedente (art. 56 del ET) y los salarios de tramitación (art. 281.2 LRJS).

Junto al despido, el art. 11 del Real Decreto regula el desistimiento del empleador, que, como decíamos, constituye una causa extintiva propia de esta relación laboral especial. La norma dispone que el empleador, en cualquier momento, podrá desistir del contrato, sin que sea necesario alegar una causa que justifique la extinción.

El desistimiento debe comunicarse por escrito al empleado, haciendo constar, de modo claro e inequívoco, la voluntad del empleador de dar por finalizada la relación laboral por esta causa. No es suficiente con la comunicación de la extinción del contrato; el empleador debe especificar que la causa de esta extinción es su desistimiento. De esta manera, el empleado queda informado de la causa extintiva, que, de otra forma, podría confundirse con el despido.

La norma impone, además, un preaviso, que, con carácter general, será de siete días, salvo que la relación laboral haya durado más de un año, en cuyo caso ha de ser, como mínimo, de veinte días. Durante el período de preaviso, el empleado contratado a jornada completa tiene derecho a un permiso retribuido de seis horas semanales para buscar un nuevo puesto de trabajo. No obstante, el empleador puede sustituir el preaviso por una indemnización equivalente a los salarios de dicho período, que se abonarán íntegramente en metálico.

En el momento de la comunicación del desistimiento, el empleador tiene la obligación de poner a disposición del empleado de hogar una indemnización, en metálico, equivalente a doce días de salario por año de servicio con el límite de seis mensualidades; la indemnización se ha incrementado sustancialmente con respecto a la prevista en la regulación anterior, que era de siete días por año de servicio, con el mismo tope máximo.

La comunicación del cese en las condiciones antes señaladas y la simultánea puesta a disposición de la indemnización son requisitos esenciales del desistimiento; si uno de estos requisitos se incumple, se presume que el empleador ha optado por el despido y no por el desistimiento y, por supuesto, el despido será improcedente. La

17 SSTSJ Castilla y León, Valladolid, 25.2.2013 (JUR 2013/119628); Castilla y León, Burgos, 7.9.2010 (AS 2010/1830); Cataluña 15.1.2013 (AS 2013/224); Madrid 24.11.2008 (AS 2009/146). 
presunción a favor del despido no opera, sin embargo, cuando se produce un incumplimiento del preaviso o un error excusable en el cálculo de la indemnización, sin perjuicio de la obligación del empleador de abonar los salarios que correspondan al período de preaviso o la parte de la indemnización que falta por pagar.

¿Podría declarase nulo el desistimiento? La aplicación del art. 55.5 del ET al desistimiento debe aceptarse, aunque con las debidas matizaciones. Este precepto establece, en su primer apartado, una regla general, en virtud de la cual el despido es nulo cuando "tenga por móvil alguna de las causas de discriminación prohibidas en la Constitución o en la Ley, o bien se produzca con violación de derechos fundamentales y libertades públicas del trabajador”. Esta regla general es plenamente aplicable al desistimiento del empleador doméstico: el desistimiento no puede responder a motivos discriminatorios ni vulnerar derechos fundamentales, por lo que, si así fuera, debería aplicarse el régimen del despido nulo, con las especialidades ya citadas en relación con la readmisión. El segundo apartado del art. 55.5 del ET enumera una serie de supuestos en los que "salvo que se declare la procedencia del despido", opera la declaración de nulidad. Estos supuestos de nulidad "automática" no son aplicables cuando se produce el desistimiento del empleador doméstico, pues en el desistimiento el empleador no tiene que justificar su decisión extintiva acreditando una determinada causa. Así lo ha entendido la doctrina judicial, que exige, en estos casos, una prueba indiciaria del móvil discriminatorio o de la lesión del derecho fundamental ${ }^{18}$.

Finalmente, el art. 11 del Real Decreto dispone que cuando el despido o el desistimiento afecten a un empleado interno, la decisión extintiva no podrá llevarse a cabo entre las diecisiete horas y las ocho horas del día siguiente, salvo que el motivo del cese sea una falta muy grave del trabajador a los deberes de lealtad y confianza.

Para facilitar las gestiones, se prevé, además, que el Ministerio ponga a disposición de los empleadores modelos de extinción del contrato de trabajo y la debida información.

En la práctica es muy probable que los empleadores domésticos opten, con carácter general, por el desistimiento, aun cuando la decisión extintiva esté motivada por un incumplimiento grave y culpable del trabajador, salvo que dicho incumplimiento sea claro y fácil de acreditar.

18 SSTSJ Cataluña, 7.10.2014 (AS 2014/2987); Asturias, 12.9.2014 (JUR 2014/250248); Madrid, 14.2.2014 (AS 2014/539). Estas sentencias citan la doctrina constitucional (STC 173/2013, de 10 de octubre) y la jurisprudencia de la Sala IV del Tribunal Supremo [STS 18.4.2011 (RJ 2011/5814)] en relación con la resolución del contrato de trabajo durante el período de prueba, en la que tampoco resulta aplicable la nulidad automática prevista en apartado segundo del art. 55.5 ET. En contra de este criterio general se pronuncia la STSJ Cataluña, 15.1.2013 (AS 2013/224), que aplica el apartado segundo del art. 55.5 del ET al despido de una empleada doméstica embarazada, que declara nulo. 


\section{BREVES REFERENCIAS A LA REFORMA DEL SISTEMA DE PROTECCIÓN SOCIAL DE LOS EMPLEADOS DEL HOGAR}

La Ley 27/2011, en su disposición adicional 39a aborda también la reforma del sistema de protección social de los empleados domésticos integrando el Régimen Especial de la Seguridad Social de los Empleados de Hogar en el Régimen General de la Seguridad Social. La integración, que entró en vigor el 1 de enero de 2012, es, sin embargo, relativa, pues se produce mediante la creación, dentro del Régimen General, de un sistema especial específico para este colectivo, el Sistema Especial de Empleados de Hogar, que tiene particularidades importantes en materia de actos de encuadramiento, cotización y acción protectora. No es posible abordar aquí un análisis exhaustivo de estas particularidades, por lo que me limitaré a una breve exposición de las más relevantes.

Es importante comenzar precisando que el campo de aplicación del Sistema Especial de Empleados de Hogar coincide plenamente con el ámbito de la relación laboral especial del servicio del hogar familiar (art. 250 del Real Decreto Legislativo 8/2015, de 30 de octubre, que aprueba el texto refundido de la Ley General de la Seguridad Social -en adelante, LGSS-). El trabajo marginal, que bajo la regulación anterior estaba excluido del Régimen Especial ${ }^{19}$, queda ahora incorporado al nuevo sistema: el trabajo doméstico se encuadra en el sistema especial con independencia del número de horas trabajadas.

En materia de actos de encuadramiento, se aplican, en principio, las reglas comunes del Régimen General. El empleador es, por tanto, el sujeto obligado a solicitar la afiliación, el alta y la baja del trabajador, así como la variación de datos; si el empleado doméstico trabaja a tiempo parcial en varios hogares, esta obligación corresponde a cada uno de sus empleadores ${ }^{20}$. No obstante, el Real Decreto-Ley 29/2012, de 28 de diciembre, ha introducido un cambio importante en esta regulación ${ }^{21}$ : a partir de 1 de abril de 2013, los trabajadores que presten servicios durante menos de sesenta horas al mes por empleador, serán los obligados a solicitar su afiliación, alta, baja y variación de datos en el sistema cuando así lo acuerden con el empleador. Para evitar fraudes, en estos casos se exige que las solicitudes vayan firmadas también por el empleador. Además, se prevé que el empleador pueda solicitar la baja cuando se produzca el cese en la prestación de servicios.

\footnotetext{
${ }^{19}$ Se entendía por trabajo marginal el que se prestaba durante un tiempo inferior a setenta y dos horas al mes distribuidas en menos de doce jornadas. La exclusión del trabajo marginal era discutible desde un punto de vista legal, pero la Dirección General de la Seguridad Social la aplicó, apelando al art. 2.1.a) del Decreto 2346/1969, de 25 de septiembre, criterio que fue respaldado por el Tribunal Central de Trabajo.

${ }^{20}$ Esto supuso un cambio radical frente a la regulación anterior, pues, en el Régimen Especial, si la prestación de servicios se realizaba por un tiempo inferior a ochenta horas al mes, estas obligaciones se imponían al empleado.

${ }^{21}$ El Real Decreto-Ley 29/2012, de 28 de diciembre, modifica el art. 43 del Reglamento General de Actos de Encuadramiento (Real Decreto 84/1996, de 26 de enero).
} 
Esta misma solución se aplica a la obligación formal de ingresar las cotizaciones. Cuando el trabajo doméstico se preste por un tiempo inferior a sesenta horas mensuales, se podrá acordar que sea el empleado el sujeto responsable del cumplimiento de la obligación de ingresar las cuotas a dicho sistema, debiendo ingresar la aportación propia y la correspondiente al empleador o empleadores con los que mantenga tal acuerdo, tanto por contingencias comunes como por contingencias profesionales. En estos casos, el empleador debe entregar al trabajador, además del recibo de salarios, la aportación y cuota que le corresponda. La responsabilidad por el incumplimiento de la obligación de cotizar en estos supuestos corresponde al propio empleado, pero el empleador responde subsidiariamente, salvo que acredite la entrega de sus aportaciones y cuotas. Para facilitar la gestión, la disposición adicional $8^{\mathrm{a}}$ del Reglamento General de Recaudación de la Seguridad Social ${ }^{22}$ dispone que el ingreso de la cotización se realizará mediante el sistema de domiciliación en cuenta abierta en una entidad financiera autorizada para actuar como oficina recaudadora de la Seguridad Social.

El sistema de cálculo de las cotizaciones, basado antes en una base de cotización única, cambia ahora sustancialmente. La disposición adicional 39a de la Ley 27/2011 establece un sistema provisional que se aplicará desde el año 2012 hasta 2018 y que tiene por objetivo aproximar paulatinamente el mecanismo de cotización de este colectivo al Régimen General, hasta su equiparación completa, que se prevé para el año 2019. En este sistema provisional, hoy incorporado a la disposición transitoria $16^{\mathrm{a}}$ de la LGSS, las bases de cotización se determinan con arreglo a una escala dividida en tramos; cada tramo relaciona la retribución mensual del empleado de hogar con una determinada base de cotización. En un principio la escala incluía quince tramos, con bases de cotización muy reducidas. Para aumentar la recaudación, el Real Decreto-Ley 29/2012 sustituyó esta escala por una nueva con ocho tramos, de cuantías superiores; además, modificó la forma de actualizar las bases de cotización, que ya no se efectúa en proporción al incremento que experimente la base mínima de cotización del Régimen General sino en proporción al incremento que experimente el salario mínimo interprofesional. Respecto a los tipos de cotización, en contingencias comunes se establece un tipo fijo para 2012 del 22\% (siendo el 18,30\% a cargo del empleador y el $3,70 \%$ a cargo del empleado), que se incrementa, cada año, en 0,90 puntos porcentuales ${ }^{23}$; en contingencias profesionales, se aplica el tipo previsto en la tarifa de primas $^{24}$. La disposición adicional $39^{\mathrm{a}}$ prevé que este sistema provisional de cotización finalice en 2018; a partir de 2019 las bases y los tipos de cotización se determinarán conforme a la regulación común del Régimen General. El empleador del hogar podrá acogerse a las bonificaciones, reducciones y exenciones de cuota previstas por la ley;

\footnotetext{
${ }^{22}$ Real Decreto 1415/2004, de 11 de junio.

${ }^{23}$ Para 2016, el tipo de cotización por contingencias comunes es el 25,60\%; siendo el 21,35\% a cargo del empleador y el 4,25\% a cargo del empleado. Vid. art. 14 de la Orden ESS/70/2016, de 29 de enero.

${ }^{24}$ La tarifa de primas se fija en la disposición adicional $4^{\text {a }}$ de la Ley 42/2006, de 28 de diciembre. Para 2016, el tipo que corresponde al servicio del hogar familiar es el 1,10\%, a cargo exclusivo del empleador.
} 
no obstante, la disposición adicional $2^{\mathrm{a}}$ del Real Decreto-Ley 29/2012 dispone que los beneficios en la cotización reconocidos por la legislación vigente a favor de los empleadores de hogar no resultarán de aplicación cuando se haya acordado que sea el empleado quien asuma las obligaciones relativas a los actos de encuadramiento y al ingreso de la cotización, previsión que reitera la disposición adicional $24^{a}$ de la LGSS. Esta medida, sin duda, desincentivará este tipo de acuerdos.

Finalmente, en relación con la acción protectora hay que señalar que, en principio, los empleados de hogar tienen derecho a las prestaciones de la Seguridad Social en los mismos términos y condiciones establecidos en el Régimen General. Se establecen, sin embargo, algunas particularidades. La más importante es la exclusión de la protección de desempleo. Esta exclusión se debe, sin duda, a razones económicas y al temor al fraude, que resulta especialmente difícil de controlar en el ámbito del hogar familiar; se trata, no obstante, de una exclusión criticable, pues provoca un vacío en la acción protectora de los empleados de hogar especialmente significativo, dada la precariedad con que se desarrolla la prestación de servicios en este sector.

\section{REFERENCIAS BIBLIOGRÁFICAS}

CUEVA PUENTE, M.C. (2005): La relación laboral especial de los empleados de hogar. Lex Nova, Valladolid.

DE SANDE PÉREZ-BEDMAR, M. (2011): La relación laboral especial de los empleados de hogar: aspectos laborales y de Seguridad Social. Revista Jurídica de la Universidad Autónoma de Madrid, $\mathrm{n}^{\circ} 23$.

GALA DURÁN, C. (2014): La protección en materia de seguridad social de los empleados de hogar tras el RDL 29/2012. En AA.VV, Relaciones laborales y empleados del hogar. Reflexiones críticas, Dykinson, Madrid.

GARCÍA VIÑA, J. (2008): Aspectos laborales de salud laboral y de seguridad social de los empleados de hogar. Comares, Granada.

LÓPEZ GANDÍA, J. \& TOSCANI GIMÉNEZ, D. (2012): El nuevo régimen laboral y de Seguridad Social de los trabajadores al servicio del hogar familiar. Bomarzo, Albacete.

MIÑARRO YANINI, M. (2013): El trabajo al servicio del hogar familiar: análisis de su nueva regulación. Reus, Madrid.

QUESADA SEGURA, R. (1991): El contrato de servicio doméstico, La Ley, Madrid.

RODRIGUEZ CARDO, I.A. (2013): El nuevo sistema especial de empleados de hogar: una revolución inconclusa. Revista Española de Derecho del Trabajo, no 158.

RODRIGUEZ CARDO, I.A. (2015): La relación laboral especial de los empleados de hogar. Revista del Ministerio de Empleo y Seguridad Social, n 118.

RUANO ALBERTOS, S. (2013): El régimen jurídico de los empleados de hogar, Atelier, Barcelona. 